DOI: https://doi.org/10.33739/2587-5434-2020-3-126-129

\title{
GEORGIAN AS A SECOND LANGUAGE - INTEGRATED LEARNING OF GEORGIAN LANGUAGE AND CIVIC EDUCATION WITHIN THE “1+4" PROGRAM
}

\author{
Ana Todua \\ Doctor of Philology \\ Ivane Javakhishvili \\ Tbilisi State University \\ (Tbilisi, Georgia) \\ e-mail: Ana.todua1988@gmail.com
}

\begin{abstract}
Integration of minorities and civil involvement are some of the most important components of the country's democratic development. The changes made in the education policy, that were executed on November 19, 2009 were aimed to strengthen integration of ethnic minorities, their access to education and civic engagement. It has been 5 years already since these changes led to establishing a successful preferential policy for ethnic Armenian and Azerbaijani high school graduates entering higher education institutions.

During this period, several educational-methodical guidelines have been developed and different methods of learning have been introduced within the framework of the Georgian Language Education Program. However, the necessity of the methodological improvement of the Georgian language learning and the introduction of modern and systematic approaches is still very essential. In the course of the study the need for pragmatic approach to language teaching became visible, where emphasis will be made on the development of communicative competence. Civic Education and the urgency of the topics given in the textbook.
\end{abstract}

Keywords: Georgian language, Georgian language teaching

\author{
ГРУЗИНСКИЙ КАК ВТОРОЙ ЯЗЫК - ИЗУЧЕНИЕ ГРУЗИНСКОГО \\ ЯЗЫКА И ГРАЖДАНСКОЕ ОБРАЗОВАНИЕ В РАМКАХ ПРОГРАММЫ$$
\text { "1+4" }
$$$$
\text { Ана Тодуа }
$$ \\ Доктор филологии \\ Иване Джавахишвили \\ Тбилисский государственный университет \\ (Тбилиси, Грузия) \\ e-mail: Ana.todua1988@gmail.com
}

\begin{abstract}
Аннотация. Интеграция меньшинств и гражданское участие являются одними из важнейших компонентов демократического развития страны. Изменения, внесенные в политику в области образования, которые были осуществлены 19 ноября 2009 года, были направлены на укрепление интеграции этнических меньшинств, их доступа к образованию и гражданской активности. Прошло уже 5 лет с тех пор, как эти изменения привели к успешному проведению преференциальной политики в отношении выпускников средних школ из числа этнических армян и азербайджанцев, поступающих в высшие учебные заведения.
\end{abstract}


За этот период было разработано несколько учебно-методических руководств, а в рамках программы обучения грузинскому языку были внедрены различные методы обучения. Однако необходимость методологического усовершенствования обучения грузинскому языку и внедрения современных и системных подходов все еще остается очень актуальной. В ходе исследования стала очевидной необходимость прагматичного подхода к обучению языку, где акцент будет сделан на развитие коммуникативной компетентности. Гражданское образование и актуальность тем, изложенных в учебнике.

Ключевые слова: грузинский язык, преподавание грузинского языка

\section{ВВЕДЕНИЕ}

Интеграция меньшинств и гражданское участие один из важнейших компонентов демократического развития страны. Информационная изоляция, которая напрямую связана с доступом к образованию для меньшинств, была названа препятствием для интеграции. Согласно последним исследованиям, этнические меньшинства в Грузии до сих пор не интегрированы в общество должным образом и являются одной из наиболее уязвимых и маргинализованных групп, отрезанных от гражданской, политической, экономической и культурной жизни страны. Поправка к политике в области образования, вступившая в силу 19 ноября 2009 года, направлена на улучшение интеграции этнических меньшинств, доступа к образованию и гражданской активности с политикой поддержки выпускников из числа этнических армян и азербайджанцев. После успешной сдачи одного из обязательных экзаменов Единого национального экзамена общих навыков на родном языке молодым людям предоставляется возможность пройти годичную программу обучения государственному языку на основе высшего образования, а затем продолжить обучение на желаемом факультете.

\section{ОБЗОР ЛИТЕРАТУРЫ}

Вот уже 10 лет грузинские вузы успешно принимают студентов из числа меньшинств на программу обучения грузинскому языку в рамках политики льготного образования. Однако следует отметить, что необходимость методологического совершенствования преподавания грузинского языка и внедрения современных, системных подходов по-прежнему актуальна. Большинство учебников ориентировано только на преподавание грузинского языка, что, по нашему опыту, с учетом специфики студентов этой программы, неэффективно, так как участие в лекционной деятельности само по себе не является гарантией развития гражданского сознания и межкультурной чувствительности этих студентов.

Несмотря на то, что они в определенной степени изучают язык, студенты из этнических меньшинств (за некоторыми исключениями) менее интегрированы в грузиноязычные общества в социокультурном плане. Имея это ввиду, учебники по программе «1 +4 » предпочтительно должны служить для повышения гражданской осведомленности учащихся. Именно в этом направлении мы будем проводить исследования посредством глубинных интервью и опросов. В рамках исследования студенты анонимно заполняли анкеты, составленные социологом: они оценивали учебники и получали от них отзывы об их потребностях и желаниях в отношении учебного процесса, метода или подхода. Было опрошено более 300 студентов. Результаты опроса показали, что студентов интересовали такие виды деятельности, как гражданское образование, информационнопознавательные и развлекательные темы; Имея это ввиду, мы решили разработать руководство в рамках программы $1+4$, с новым методом и подходом (интегрированное обучение языку и гражданское образование), которое будет сосредоточено на развитии коммуникативной компетенции в процессе обучения. 


\section{МЕТОДЫ ИССЛЕДОВАНИЯ}

Такой подход к обучению языку предполагает разнообразие и систематическое изменение типов тем и текстов, потому что в рамках этого метода обучения ученик считается не только пассивным участником, но и со-творцом знаний. В качестве рефлексии мы решили создать подход - метод, который бы соответствовал специфике программы «1 +4 ». В связи с тем, что студенты были менее интегрированы в грузиноязычное сообщество, менее активны в гражданской деятельности, был выбран метод интеграции грузинского и гражданского образования.

\section{РЕЗУЛЬТАТЫ И ДИССКУССИЯ}

Согласно одной из наиболее распространенных идей: «Интегрированное изучение языка и предмета (CLIL) - это двухфокусный образовательный подход, при котором дополнительный язык используется для обучения и преподавания как содержания, так и языка. CLIL основан на содержательном обучении и, таким образом, расширяет возможности изучения языка и отличается от существующих подходов к преподаванию языков». Будет направлено на повышение гражданской осведомленности.

Почему гражданское образование? Забота о гражданском сознании молодых людей начинается в школьном возрасте и включает в себя развитие таких важных навыков, как: оценка и корректировка своего собственного отношения и поведения, понимание и защита прав и обязанностей себя и других людей, участие в гражданской деятельности и волонтерстве, постановка целей; Формулирование идей, инициатив и способов их реализации, забота о безопасности жизни и чрезвычайных ситуаций, ведение здорового образа жизни и многое другое. Список, как видим, довольно большой и тоже актуальный.

\section{ЗАКЛЮЧЕНИЕ}

Учитывая специфику, наша цель: 1. Содействовать социальной и культурной интеграции армянских и азербайджанских студентов из национальных меньшинств в грузиноязычную среду; 2. Расширение знаний, внедрение сложных мероприятий в аудитории, наряду с обучением языку, повышение компетенций учащихся в разных областях. (например, Формулировка-обоснование собственного мнения, методы убеждения, изложения, творческие способности и др.); 3. Настройка формата календаря для учебного процесса; С учетом всего этого был написан проект «Календарь Земли», который уже профинансирован и реализован Фондом «Открытое общество Грузии». В рамках проекта разработано методическое пособие, которое уже апробировано в программе $1+4$ в пилотном режиме.

Мы думаем, что корректировка формата календаря становится для преподавателя методическим инструментом. В дополнение к наличию готовых материалов и учебных ресурсов, доступных преподавателю посредством различных занятий, он также имеет возможность планировать свою собственную аудиторную работу, чтобы размышлять о современности, реальности и развивать коммуникативные навыки учащегося.

Примечательно, что, познавая и участвуя в важных датах, ученик получает возможность расширить свое поле зрения, воспринять свою культуру в контексте других культур; больше интегрироваться в грузиноязычный мир и в то же время воспринимать себя как гражданина мира.

Поскольку метод предполагает интегрированное обучение языку и гражданское образование, каждая тема, представленная в книге, включает комплексные языковые и предметные занятия, с повышением гражданской осведомленности учащийся осваивает второй язык. Речевые функции - обработка во всех четырех направлениях представлена следующим образом: 
Устная речь: аудиоматериалы, фильмы; Словарь: тест / викторина, наглядные диаграммы; Вопрос: тест / викторина, обсуждение, наглядные схемы; Написание: тест / викторина, наглядные схемы, творческие задания; Дополнительные занятия: игры, презентации, групповые занятия.

Для апробации метода и подтверждения его эффективности в рамках проекта было проведено исследование и серия тренингов на его основе, а также пилотное пособие для подготовительной программы ТГУ «Земной календарь» в течение семестра в пилотном режиме.

Можно сказать, что подход оказался удачным. В конце семестра была проведена обратная связь, которая подтвердила эффективность интегрированного обучения языку и гражданскому образованию и актуальность тем, представленных в учебнике.

Следовательно, мы считаем, что внедрение интегрированного обучения языку и предметам становится эффективным средством овладения языком на университетском уровне. Такой подход поможет студентам программы «1 +4 » повысить не только языковую, но и гражданскую осведомленность.

\section{LIST OF REFERENCES}

Coyle, D. (2008). CLIL - a pedagogical approach. In N. Van Deusen-Scholl, \& N. Hornberger, Encyclopedia of Language and Education, 2nd edition (pp. 97-111). Springer.

Coyle, D., Hood, P., \& Marsh, D. (2010). Content and language integrated learning. Cambridge: Cambridge University Press.

Coyle, D., Hud, F. \& Marsh, D. CLIL: Content and Language Integrated Learning. Cambridge University Press https://assets.cambridge.org/97805211/30219/excerpt/9780521130219 excerpt.pdf

Sakartvelos Gaeros Asotsiatsia „Erovnuli Int'egratsiis Gadzliereba Sakartveloshi“ - Samokalako Int'egr. k'vleva (2014).

\section{For citation:}

Todua, A. (2020) Georgian as a second language - integrated learning of Georgian language and civic education within the " $1+4$ " program // International Scientific-Pedagogical Organization of Philologists " WEST-EAST" (ISPOP). Scientific Journal "WEST-EAST” Vol. 3, N1 (October, 2020). pp. 126-129. https://doi.org/10.33739/2587-5434-20203-126-129

\section{Для цитирования:}

Тодуа, А. (2020) Грузинский как второй язык - изучение грузинского языка и гражданское образование в рамках программы "1+4" // International Scientific-Pedagogical Organization of Philologists "WEST-EAST" (ISPOP). Scientific Journal "WEST-EAST" Vol.3, N1 (October, 2020). C. 126-129. https://doi.org/10.33739/25875434-2020-3-126-129

Information about the author: Todua $\mathrm{Ana}-\mathrm{PhD}$ in Philology, Ivane Javakhishvili Tbilisi State University, Tbilisi, Georgia. e-mail: Ana.todua1988@gmail.com

Сведения об авторе: Тодуа Ана - доктор филологии, Тбилисский государственный университет им. Иване Джавахишвили, Тбилиси, Грузия. e-mail: Ana.todua1988@gmail.com 